Experimental Allergy and Immunology

\title{
Transfer of innovation on allergic rhinitis and asthma multimorbidity in the elderly (MACVIA-ARIA) - EIP on AHA Twinning Reference Site (GARD research demonstration project)
}
J. Bousquet ${ }^{1,2,3}$
I. Agache ${ }^{4}$
M. R. Aliberti ${ }^{5}$
R. Angles ${ }^{6}$
I. Annesi-Maesano ${ }^{7,8}$
J. M. Anto $9,10,11$
S. Arnavielhe ${ }^{12}$
E. Asayag ${ }^{13}$
E. Bacci ${ }^{14}$
A. Bedbrook ${ }^{1}$

C. Bachert ${ }^{15}$ | I. Baroni ${ }^{16}$

B. A. Barreto ${ }^{17}$

M. Bedolla-Barajas ${ }^{18}$

K. C. Bergmann ${ }^{19,20}$

L. Bertorello ${ }^{14}$

M. Bewick ${ }^{21}$

T. Bieber ${ }^{22}$

S. Birov 23

C. Bindslev-Jensen ${ }^{24}$

A. Blua $^{25}$

M. Bochenska Marciniak ${ }^{26}$

I. Bogus-Buczynska ${ }^{26}$

S. Bosnic-Anticevich ${ }^{27}$

I. Bosse 28

R. Bourret ${ }^{29}$

C. Bucca ${ }^{30}$

R. Buonaiuto ${ }^{31}$

M. T. Burguete Cabanas ${ }^{32}$

D. Caillaud ${ }^{34}$

D. P. Caimmi ${ }^{35}$

D. Caiazza ${ }^{31}$

P. Camargos ${ }^{36}$

G. Canfora $^{37}$ | V. Cardona ${ }^{38}$

A. M. Carriazo ${ }^{39}$

C. Cartier ${ }^{40}$ ।

G. Castellano ${ }^{41}$

N. H. Chavannes ${ }^{42}$

L. Cecci ${ }^{43}$

M. M. Ciaravolo ${ }^{44}$

C. Cingi ${ }^{45}$
A. Ciceran ${ }^{46}$
L. Colas ${ }^{47}$
E. Colgan ${ }^{48}$
D. Conforti ${ }^{50}$
J. Correia de

Sousa $^{51}$ | R. M. Cortés-Grimaldo ${ }^{52}$

E. Cousein ${ }^{56}$

A. A. $\mathrm{Cruz}^{57,58}$

A. Custovic ${ }^{59}$

F. Corti ${ }^{53}$

E. Costa ${ }^{54}$

B. Cvetkovski ${ }^{27}$

A. L. Courbis ${ }^{55}$

J. da Silva ${ }^{61}$

Y. Dauvilliers ${ }^{62}$

F. De Blay ${ }^{63}$

T. Dedeu ${ }^{64}$

G. De $\mathrm{Feo}^{65}$
G. De Vries ${ }^{67}$

S. Di Capua Ercolano 68
B. De

C. Dario ${ }^{60}$

N. Di Carluccio ${ }^{31}$
M. Doulapsi ${ }^{69}$
G. Dray ${ }^{55}$
R. Dubakiene ${ }^{70}$
E. Eller ${ }^{24}$
R. Emuzyte ${ }^{71}$ |
J. G. Espinoza-Contreras ${ }^{72}$
A. Estrada-Cardona ${ }^{73}$
J. Farrell ${ }^{48}$
A. Farsi ${ }^{43}$

J. Ferrero ${ }^{74}$

W. J. Fokkens ${ }^{75}$

J. Fonseca ${ }^{76,77}$

| J. F. Fontaine ${ }^{78}$

S. Forti ${ }^{50}$

J. L. Gálvez-Romero ${ }^{79}$

C. I. García-Cobas ${ }^{80}$

M. H. Garcia Cruz ${ }^{81}$

B. Gemicioğlu ${ }^{82}$

R. Gerth van Wijk ${ }^{83} \mid$ M. Guidacci ${ }^{84}$ | J. Gómez-Vera ${ }^{85}$ | N. A. Guldemond ${ }^{86}$

Z. Gutter ${ }^{87} \mid$ T. Haahtela ${ }^{88}$ | J. Hajjam ${ }^{89}$ | P. W. Hellings ${ }^{90}$ | L. Hernández-



O. Kalayci ${ }^{98}$

A. F. Kalyoncu ${ }^{99}$

J. Karjalainen ${ }^{100}$

T. Keil ${ }^{101}$

N. Khaltaev ${ }^{102}$

L. Klimek ${ }^{103}$

V. Kritikos ${ }^{27}$ | I. Kull ${ }^{104}$

P. Kuna ${ }^{26}$

V. Kvedariene ${ }^{105}$

V. Kolek ${ }^{106}$

Abbreviations: AHA, Active and Healthy Aging; AIT, specific immunotherapy; AR, allergic rhinitis; ARIA, Allergic Rhinitis and its Impact on Asthma; CARAT, Control of Allergic Rhinitis and Asthma Test; EIP, European Innovation Partnership; EU, European Union; HIT, Health information technology; ICT, information and communications technology; MACVIA, Contre les MAladies Chroniques pour un Vlellissement Actif; MASK, MACVIA-ARIA Sentinel NetworK; NAR, non allergic rhinitis; SCUAD, Severe chronic upper airways disease; VAS, visual analogue scale. 
E. Krzych-Fałta ${ }^{107}$ | M. Kupczyk ${ }^{26}$ | P. Lacwik ${ }^{26}$ | S. La Grutta108 | D. Larenas-
Linnemann $^{109}$
D. Laune ${ }^{12}$
D. Lauri ${ }^{110}$
J. Lavrut ${ }^{111}$
M. Lessa ${ }^{112}$
G. Levato ${ }^{113}$

L. Lewis $^{114}$ | I. Lieten ${ }^{115}$ | A. Lipiec ${ }^{107}$ | R. Louis ${ }^{116}$ | J. A. Luna-Pech ${ }^{117}$
A. Magnan 47
J. Malva ${ }^{118,119}$
J. F. Maspero ${ }^{120}$
J. J. Matta-Campos ${ }^{121}$
O. Mayora 50
M. A. Medina-Ávalos ${ }^{122}$
E. Melén ${ }^{123}$
E. Menditto ${ }^{124}$

J. Millot-Keurinck ${ }^{125}$ | G. Moda ${ }^{126}$ | M. Morais-Almeida ${ }^{127}$ | R. Mösges ${ }^{128}$

A. Mota-Pinto ${ }^{119,129,130}$ | J. Mullol ${ }^{131}$ | A. Muraro ${ }^{132}$ | R. Murray ${ }^{133}$ | M. Noguès ${ }^{125}$ |

M. Nalin ${ }^{16}$ | L. Napoli ${ }^{134}$ | H. Neffen ${ }^{135}$

\begin{tabular}{l|l} 
R. E. O'Hehir & 136 \\
| G. L. Onorato & 1
\end{tabular}

S. Palkonen ${ }^{137}$

N. G. Papadopoulos ${ }^{138,139}$

G. Passalacqua ${ }^{140}$ | J. L. Pépin ${ }^{141}$ |
A. M. Pereira ${ }^{142}$
M. Persico ${ }^{143}$
O. Pfaar ${ }^{144,145}$
A. C. Pozzi ${ }^{146}$
E. Prokopakis ${ }^{69}$
B. Pugin ${ }^{90}$ | F. Raciborski ${ }^{107}$
J. Rimmer ${ }^{147}$
J. A. Rizzo ${ }^{148}$
C. Robalo-Cordeiro ${ }^{149}$

M. Rodríguez-González ${ }^{150}$

G. Rolla 151

R. E. Roller-Wirnsberger ${ }^{152}$
A. Romano ${ }^{153,154}$
M. Romano ${ }^{16}$
M. R. Romano 5
J. Salimäki ${ }^{155}$
B. Samolinski $i^{107}$
F. S. Serpa ${ }^{156}$
S. Shamai ${ }^{128}$
M. Sierra ${ }^{49}$
M. Sova ${ }^{157}$
M. Sorlini ${ }^{158}$
C. Stellato ${ }^{65}$
R. Stelmach ${ }^{159}$
T. Strandberg ${ }^{160}$
| V. Stroetmann ${ }^{23}$
R. Stukas ${ }^{161}$
A. Szylling ${ }^{107}$
R. $\operatorname{Tan}^{27}$
V. Tibaldi ${ }^{151}$
A. Todo-Bom ${ }^{162}$
S. Toppila-Salmi ${ }^{88}$

P. Tomazic ${ }^{163}$

U. Trama ${ }^{164}$

M. Triggiani ${ }^{65}$

A. Valero ${ }^{165}$

E. Valovirta ${ }^{166,167}$

A. Valiulis ${ }^{168,169} \mid$ M. van Eerd ${ }^{67} \mid$ T. Vasankari ${ }^{170}$ | A. Vatrella ${ }^{65}$ | M. T. Ventura ${ }^{171}$ |

M. T. Verissimo ${ }^{118,119}$

F. Viart ${ }^{40}$

S. Williams ${ }^{172}$

M. Wagenmann ${ }^{173}$

C. Wanscher ${ }^{174}$

M. Westman ${ }^{175}$

M. Wickman ${ }^{176}$

I. Young ${ }^{177}$ |
A. Yorgancioglu ${ }^{178}$
E. Zernotti ${ }^{179}$
T. Zuberbier ${ }^{19,20}$
A. Zurkuhlen ${ }^{33}$
B. De Oliviera ${ }^{180}$
A. Senn ${ }^{180}$

${ }^{1}$ MACVIA-France, Contre les MAladies Chroniques pour un Vleillissement Actif en France European Innovation Partnership on Active and Healthy Ageing Reference Site, Montpellier, France

${ }^{2}$ VIMA, INSERM U 1168, VIMA: Ageing and Chronic Diseases, Epidemiological and Public Health Approaches, Villejuif, France

${ }^{3}$ Université Versailles St-Quentin-en-Yvelines, UMR-S 1168, Montigny le Bretonneux, France

${ }^{4}$ Faculty of Medicine, Transylvania University, Brasov, Romania

${ }^{5}$ Municipality of Salerno, Salerno, Italy

${ }^{6}$ Innovación y nuevas tecnologías, Salud Sector sanitario de Barbastro, Barbastro, Spain

${ }^{7}$ EPAR U707 INSERM, Paris, France

${ }^{8}$ EPAR UMR-S UPMC, Paris VI, Paris, France

${ }^{9}$ ISGLoBAL, Centre for Research in Environmental Epidemiology (CREAL), Barcelona, Spain

${ }^{10}$ IMIM (Hospital del Mar Research Institute), Universitat Pompeu Fabra (UPF), Barcelona, Spain

${ }^{11}$ CIBER Epidemiología y Salud Pública (CIBERESP), Universitat Pompeu Fabra (UPF), Barcelona, Spain

${ }^{12}$ Kyomed, Montpellier, France

${ }^{13}$ Argentine Society of Allergy and Immunopathology, Buenos Aires, Argentina

${ }^{14}$ Regione Liguria, Genoa, Italy

${ }^{15}$ Upper Airways Research Laboratory, ENT Department, Ghent University Hospital, Ghent, Belgium

${ }^{16}$ Telbios SRL, Milan, Italy

${ }^{17}$ Alergologo, Belem, Brazil 
${ }^{18}$ Hospital Civil de Guadalajara Dr. Juan I. Menchaca, Guadalarara, Mexico

${ }^{19}$ Comprehensive Allergy-Centre-Charité, Department of Dermatology and Allergy, Charité-Universitätsmedizin Berlin, Berlin, Germany

${ }^{20}$ Global Allergy and Asthma European Network (GA 2 LEN), Berlin, Germany

${ }^{21}$ iQ4U Consultants Ltd, London, UK

${ }^{22}$ Department of Dermatology and Allergy, Rheinische Friedrich-Wilhelms-University, Bonn, Germany

${ }^{23}$ Empirica Communication and Technology Research, Bonn, Germany

${ }^{24}$ Department of Dermatology and Allergy Centre, Odense University Hospital, Odense, Denmark

${ }^{25}$ Argentine Association of Respiratory Medicine, Buenos Aires, Argentina

${ }^{26}$ Division of Internal Medicine, Asthma and Allergy, Barlicki University Hospital, Medical University of Lodz, Lodz, Poland

${ }^{27}$ Woolcock Institute of Medical Research, University of Sydney and Sydney Local Health District, Glebe, NSW, Australia

${ }^{28}$ Allergist, La Rochelle, France

${ }^{29}$ Centre Hospitalier Valenciennes, Valenciennes, France

${ }^{30}$ Chief of the University Pneumology Unit- AOU Molinette, Hospital City of Health and Science of Torino, Torino, Italy

${ }^{31}$ Pharmacist of COFASER - Consorzio Farmacie Servizi-Salerno, Salerno, Italy

${ }^{32}$ Centro Médico Zambrano Hellion, Monterrey, Mexico

${ }^{33}$ Gesundheitsregion KölnBonn - HRCB Projekt GmbH, Kohln, Germany

${ }^{34}$ Service de pneumologie, $\mathrm{CHU}$ et université d'Auvergne, Clermont-Ferrand, France

${ }^{35}$ Department of Respiratory Diseases, Montpellier University Hospital, Montpellier, France

${ }^{36}$ Department of Pediatrics, Medical School, Federal University of Minas Gerais, Belo Horizonte, Brazil

${ }^{37}$ Mayor of Sarno and President of Salerno Province, Anesthesiology Service, Sarno "Martiri del Villa Malta" Hospital, Sarno, Italy

${ }^{38}$ S. Allergologia, S. Medicina Interna, Hospital Vall d'Hebron, Barcelona, Spain

${ }^{39}$ Regional Ministry of Health of Andalusia, Seville, Spain

${ }^{40}$ ASA - Advanced Solutions Accelerator, Clapiers, France

${ }^{41}$ Celentano Pharmacy, Massa Lubrense, Italy

${ }^{42}$ Department of Public Health and Primary Care, Leiden University Medical Center, Leiden, The Netherlands

${ }^{43}$ S.O.S Allergology and Clinical Immunology, USL Toscana Centro, Prato, Italy

${ }^{44}$ Specialist Social Worker, Sorrento, Italy

${ }^{45}$ ENT Department, Medical Faculty, Eskisehir Osmangazi University, Eskisehir, Turkey

${ }^{46}$ Argentine Federation of Otorhinolaryngology Societies, Buenos Aires, Argentina

${ }^{47}$ Service de Pneumologie, UMR INSERM, UMR1087and CNR 6291, l'institut du thorax, University of Nantes, Nantes, France

${ }^{48}$ Department of Health, Social Services and Public Safety, Belfast, UK

${ }^{49}$ Innovación y nuevas tecnologías, Salud Sector sanitario de Barbastro, Barbastro, Spain

${ }^{50}$ Fondazione Bruno Kessler (FBK), Trento, Italy

${ }^{51}$ Life and Health Sciences Research Institute (ICVS), School of Health Sciences, University of Minho, Braga, Portugal

${ }^{52}$ Alergologa, Guadalarara, Mexico

${ }^{53}$ FIMMG (Federazione Italiana Medici di Medicina Generale), Milan, Italy

${ }^{54}$ UCIBIO, REQYULTE, Faculty of Pharmacy and Competence Center on Active and Healthy Ageing of University of Porto (AgeUPNetWork), Porto, Portugal

${ }^{55}$ Ecole des Mines, Alès, France

${ }^{56}$ Vice Président de la CME - Centre Hospitalier, Valenciennes, France

${ }^{57}$ ProAR - Nucleo de Excelencia em Asma, Federal University of Bahia, Bahia, Brazil

${ }^{58}$ GARD/WHO Executive Committee and Federal University of Bahia, Bahia, Brazil

${ }^{59}$ Department of Pediatric, Imperial College London, London, UK

${ }^{60}$ Azienda Provinciale per i Servizi Sanitari di Trento (APSS-Trento), Trento, Italy

${ }^{61}$ Allergy Service, University Hospital of Federal University of Santa Catarina (HU-UFSC), Florianópolis, Brazil

${ }^{62}$ Sleep Unit, Department of Neurology, Hôpital Gui-de-Chauliac Montpellier, Inserm U1061, Montpellier, France

${ }^{63}$ Allergy Division, Chest Disease Department, University Hospital of Strasbourg, Strasbourg, France

${ }^{64}$ AQuAS, Barcelona, Spain \& EUREGHA, European Regional and Local Health Association, Brussels, Belgium

${ }^{65}$ Department of Medicine, Surgery and Dentistry "Scuola Medica Salernitana”, University of Salerno, Salerno, Italy

${ }^{66}$ Social Workers Coordinator, Sorrento, Italy

${ }^{67}$ Peercode DV, Gerdermalsen, The Netherlands

${ }^{68}$ Farmacie Dei Golfi Group, Massa Lubrense, Italy

${ }^{69}$ Department of Otolaryngology, University of Crete School of Medicine, Heraklion, Greece

${ }^{70}$ Medical Faculty, Vilnius University, Vilnius, Lithuania 
${ }^{71}$ Clinic of Children's Diseases, Faculty of Medicine, Vilnius University, Vilnius, Lithuania

${ }^{72}$ University of Aguascalientes, Chihuaha, Mexico

${ }^{73}$ Alergologo, Playa del Carmen, Mexico

${ }^{74}$ Andalusian Agency for Healthcare Quality, Seville, Spain

${ }^{75}$ Department of Otorhinolaryngology, Academic Medical Centre, Amsterdam, The Netherlands

${ }^{76}$ Center for Health Technology and Services Research- CINTESIS, Faculdade de Medicina, Universidade do Porto, Porto, Portugal

${ }^{77}$ Allergy Unit, CUF Porto Instituto \& Hospital, Porto, Portugal

${ }^{78}$ Allergist, Reims, France

${ }^{79}$ Regional Hospital of ISSSTE, Puebla, Mexico

${ }^{80}$ Alergologo, Guadalarara, Mexico

${ }^{81}$ Allergy Clinic, National Institute of Respiratory Diseases, Mexico City, Mexico

${ }^{82}$ Department of Pulmonary Diseases, Cerrahpasa Faculty of Medicine, Istanbul University, Istanbul, Turkey

${ }^{83}$ Department of Internal Medicine, Section of Allergology, Erasmus MC, Rotterdam, The Netherlands

${ }^{84}$ Member of the Brazilian Society of Pediatrics and Society of Immunization, Representative of GINA (Global Initiative Against Asthma), Brasilia, Brazil

${ }^{85}$ Allergy Clinic, Hospital Regional del ISSSTE 'Lic. López Mateos', Mexico City, Mexico

${ }^{86}$ Institute of Health Policy and Management iBMG, Erasmus University, Rotterdam, The Netherlands

${ }^{87}$ University Hospital Olomouc - National eHealth Centre, Olomouk, Czech Republic

${ }^{88}$ Skin and Allergy Hospital, Helsinki University Hospital, Helsinki, Finland

${ }^{89}$ Centich: centre d'expertise national des technologies de l'information et de la communication pour l'autonomie, Gérontopôle autonomie longévité des Pays de la Loire, Conseil régional des Pays de la Loire, Centre d'expertise Partenariat Européen d'Innovation pour un vieillissement actif et en bonne santé, Nantes, France

${ }^{90}$ Laboratory of Clinical Immunology, Department of Microbiology and Immunology, KU Leuven, Leuven, Belgium

${ }^{91}$ Alergologo, Ensenada, Mexico

${ }^{92}$ Division for Health Innovation, Campania Region and Federico II University Hospital Naples (R\&D and DISMET), Naples, Italy

${ }^{93}$ Servicio de Alergia e Immunologia, Clinica Santa Isabel, Buenos Aires, Argentina

${ }^{94}$ Libra Foundation, Buenos Aires, Argentina

${ }^{95}$ Department of Respiratory Medicine, Ghent University Hospital, Ghent, Belgium

${ }^{96}$ Allergology Department, Centre de l'Asthme et des Allergies, Hôpital d'Enfants Armand-Trousseau (APHP, Paris), Paris, France

${ }^{97}$ Sorbonne Universités, UPMC Univ Paris 06, UMR_S 1136, Institut Pierre Louis d'Epidémiologie et de Santé Publique, Equipe EPAR, Paris, France

${ }^{98}$ Pediatric Allergy and Asthma Unit, Hacettepe University School of Medicine, Ankara, Turkey

${ }^{99}$ Immunology and Allergy Division, Department of Chest Diseases, School of Medicine, Hacettepe University, Ankara, Turkey

${ }^{100}$ Allergy Centre, Tampere University Hospital, Tampere, Finland

${ }^{101}$ Institute of Social Medicine, Epidemiology and Health Economics, Charité - Universitätsmedizin Berlin, Berlin, and Institute for Clinical Epidemiology and Biometry, University of Wuerzburg, Wuerzburg, Germany

${ }^{102}$ GARD, Geneva, Switzerland

${ }^{103}$ Center for Rhinology and Allergology, Wiesbaden, Germany

${ }^{104}$ Department of Clinical Science and Education, Södersjukhuset, Karolinska Institutet, Stockholm, Sweden

${ }^{105}$ Clinic of Infectious, Chest Diseases, Dermatology and Allergology, Vilnius University, Vilnius, Lithuania

${ }^{106}$ Department of Respiratory Medicine, Faculty of Medicine and Dentistry, University Hospital, Olomouc, Czech Republic

${ }^{107}$ Department of Prevention of Environmental Hazards and Allergology, Medical University of Warsaw, Warsaw, Poland

${ }^{108}$ Institute of Biomedicine and Molecular Immunology (IBIM), National Research Council (CNR), Palermo, Italy

${ }^{109}$ Clínica de Alergia, Asma y Pediatría, Hospital Médica Sur, México City, Mexico

${ }^{110}$ Presidente CMMC, Milano, Italy

${ }^{111}$ Head of the Allergy Department of Pedro de Elizalde Children's Hospital, Buenos Aires, Argentina

${ }^{112}$ Faculdade de Medicina da Universidade Federal da Bahia, Salvador de Bahia, Brazil

${ }^{113}$ Sifmed, Milano, Italy

${ }^{114}$ Promotor B3 Action GRoup EIP on AHA and Senior Fellow, International Foundation for Integreted Care, Aberystwyth, UK

${ }^{115}$ Tech Life Valley, Diepenbeek, Belgium

${ }^{116}$ Department of Pulmonary Medicine, CHU Sart-Tilman, Liege, Belgium

${ }^{117}$ University of Guadalajara, Guadalara, Mexico

${ }^{118}$ Faculty of Medicine, Institute of Biomedical Imaging and Life Sciences (IBILI), University of Coimbra, Coimbra, Portugal

${ }^{119}$ Ageing@Coimbra EIP-AHA Reference Site, Coimbra, Portugal

${ }^{120}$ Argentine Association of Allergy and Clinical Immunology, Buenos Aires, Argentina 
${ }^{121}$ Hospital Regional Siglo XXI, Mexico City, Mexico

${ }^{122}$ Alergologo, Veracruz, Mexico

${ }^{123}$ Sachs' Children and Youth Hospital, Södersjukhuset, Stockholm and Institute of Environmental Medicine, Karolinska Institutet, Stockholm, Sweden

${ }^{124}$ CIRFF, Federico II University, Naples, Italy

${ }^{125}$ Caisse d'assurance retraite et de la santé au travail du Languedoc-Roussillon (CARSAT-LR), Montpellier, France

${ }^{126}$ Regione Piemonte, Torino, Italy

${ }^{127}$ Allergy and Clinical Immunology Department, Hospital CUF-Descobertas, Lisboa, Portugal

${ }^{128}$ Institute of Medical Statistics, Informatics and Epidemiology, Medical Faculty, University of Cologne, Cologne, Germany

${ }^{129}$ Laboratory of General Pathology, Faculty of Medicine, University of Coimbra, Coimbra, Portugal

${ }^{130}$ Institute of Biomedical Imaging and Life Sciences (IBILI), Faculty of Medicine, University of Coimbra, Coimbra, Portugal

${ }^{131}$ Clinical \& Experimental Respiratory Immunoallergy, ENT Department, Hospital Clínic, IDIBAPS, Universitat de Barcelona, Barcelona, Spain

${ }^{132}$ Department of Women and Child Health, Food Allergy Referral Centre Veneto Region, Padua General University Hospital, Padua, Italy

${ }^{133}$ MedScript Ltd, Dundalk, Co. Louth, Ireland

${ }^{134}$ Consortium of Pharmacies and Services COSAFER, Salerno, Italy

${ }^{135} \mathrm{Head}$ of Respiratory Medicine, Alassia Children's Hospital, Center for Allergy and Immunology, Santa Fe, Argentina

${ }^{136}$ Department of Allergy, Immunology and Respiratory Medicine, Alfred Hospital and Central Clinical School, Monash University, Melbourne, Vic., Australia

${ }^{137}$ EFA European Federation of Allergy and Airways Diseases Patients' Associations, Brussels, Belgium

${ }^{138}$ Center for Pediatrics and Child Health, Institute of Human Development, Royal Manchester Children's Hospital, University of Manchester, Manchester, UK

${ }^{139}$ Allergy Department, 2nd Pediatric Clinic, Athens General Children's Hospital "P\&A Kyriakou”, University of Athens, Athens, Greece

${ }^{140}$ Allergy and Respiratory Diseases, IRCCS San Martino Hospital-IST-University of Genoa, Genoa, Italy

${ }^{141}$ Department of Pneumology, CHU Grenoble, Grenoble, France

${ }^{142}$ Allergy Unit, CUF-Porto Hospital and Institute, Center for Research in Health Technologies and Information Systems, CINTESIS, Universidade do Porto, Porto, Portugal

${ }^{143}$ Sociologist, Municipality, Sorrento, Italy

${ }^{144}$ Department of Otorhinolaryngology, Head and Neck Surgery, Universitätsmedizin Mannheim, Medical Faculty Mannheim, Heidelberg University, Mannheim, Germany

${ }^{145}$ Center for Rhinology and Allergology, Wiesbaden, Germany

${ }^{146}$ Vice-Presidente of IML, Milano, Italy

${ }^{147}$ Woolcock Institute of Medical Research, University of Sydney and Sydney Local Health District, Glebe, NSW, Australia

${ }^{148}$ Alergista, Recife, Brazil

${ }^{149}$ Centre of Pneumology, Coimbra University Hospital, Coimbra, Portugal

${ }^{150}$ Alergologo, Mexico City, Mexico

${ }^{151}$ Regione Piemonte, Torino, Italy

${ }^{152}$ Medical University of Graz, Graz, Austria

${ }^{153}$ Allergy Unit, Presidio Columbus, Rome, Catholic University of Sacred Heart, Rome, Italy

${ }^{154}$ IRCCS Oasi Maria S.S., Troina, Italy

${ }^{155}$ Association of Finnish Pharmacists, Helsinki, Finland

${ }^{156}$ Allergist, Vitoria, Brazil

${ }^{157}$ Departement of Internal Medicine, University Hospital, Olomouc, Czech Republic

${ }^{158}$ IML (Lombardy Medical Initiative), Bergamo, Italy

${ }^{159}$ Pulmonary Division, Heart Institute (InCor), Hospital da Clinicas da Faculdade de Medicina da Universidade de Sao Paulo, Sao Paulo, Brazil

${ }^{160}$ Center for Life Course Health Research, Helsinki University Hospital, Helsinki University, University of Oulu, Oulu, Finland

${ }^{161}$ Public Health Institute of Vilnius University, Vilnius, Lithuania

${ }^{162}$ Imunoalergologia, Centro Hospitalar Universitário de Coimbra and Faculty of Medicine, University of Coimbra, Coimbra, Portugal

${ }^{163}$ Department of ENT, Medical University of Graz, Graz, Austria

${ }^{164}$ Division on Pharmacy and Devices Policy, Campania Region, Naples, Italy

${ }^{165}$ Pneumology and Allergy Department, Hospital Clínic, Clinical \& Experimental Respiratory Immunoallergy, IDIBAPS, CIBERES, University of Barcelona, Barcelona, Spain

${ }^{166}$ Department of Lung Diseases and Clinical Allergology, University of Turku, Turku, Finland

${ }^{167}$ Allergy Clinic, Terveystalo, Turku, Finland

${ }^{168}$ Vilnius University Clinic of Children's Diseases and Public Health Institute, Vilnius, Lithuania

${ }^{169}$ European Academy of Paediatrics (EAP/UEMS-SP), Brussels, Belgium

${ }^{170}$ FILHA, Finnish Lung Association, Helsinki, Finland 




\section{Correspondence}

Jean Bousquet, CHU Arnaud de Villeneuve,

Montpellier Cédex 5, France.

Email: jean.bousquet@orange.fr

\section{Funding information}

This study received an unrestricted educational grant from Meda (Bad Homburg, Germany) and Structural Development Funds from the European Union (Région Languedoc Roussillon). The app belongs to the Région Occitanie (formerly LanguedocRoussillon, Midi-Pyrénées, France). MASK is a project of the B3 Action Plan of the European Innovation Partnership on Active and Healthy Ageing - EIP on AHA (European Commission DG Santé and DG CONNECT) and of the "Twinning" (Transfer of Innovation, 2016 Pilot Twinning Support Scheme of the EIP on AHA) of the app in 22 EIP on AHA Reference Sites.

Edited by: Hans-Uwe Simon

[Correction added on 28 November 2017 after first online publication: One of the author names was previously incorrect and has been corrected in this version.]

\begin{abstract}
The overarching goals of the European Innovation Partnership on Active and Healthy Ageing (EIP on AHA) are to enable European citizens to lead healthy, active and independent lives whilst ageing. The EIP on AHA includes 74 Reference Sites. The aim of this study was to transfer innovation from an app developed by the MACVIA-France EIP on AHA reference site (Allergy Diary) to other reference sites. The phenotypic characteristics of rhinitis and asthma multimorbidity in adults and the elderly will be compared using validated information and communication technology (ICT) tools (i.e. the Allergy Diary and CARAT: Control of Allergic Rhinitis and Asthma Test) in 22 Reference Sites or regions across Europe. This will improve the understanding, assessment of burden, diagnosis and management of rhinitis in the elderly by comparison with an adult population. Specific objectives will be: (i) to assess the percentage of adults and elderly who are able to use the Allergy Diary, (ii) to study the phenotypic characteristics and treatment over a 1-year period of rhinitis and asthma multimorbidity at baseline (cross-sectional study) and (iii) to follow-up using visual analogue scale (VAS). This part of the study may provide some insight into the differences between the elderly and adults in terms of response to treatment and practice. Finally (iv) work productivity will be examined in adults.
\end{abstract}

\section{KEYWORDS}

Allergy, Allergy Diary, asthma, European Innovation Partnership on Active and Healthy Ageing, rhinitis

\section{1 | INTRODUCTION}

Rhinitis, the most common chronic disease in Europe, often starts early in life, persists across the life cycle and causes a high disease burden in all age groups. ${ }^{1}$ Rhinitis and asthma multimorbidity is common ${ }^{1}$ and the two diseases should be considered jointly. The symptoms of allergic rhinitis (AR) can cause considerable morbidity in terms of physical and emotional comfort and functional capacity. Work productivity is one of the major societal impacts of $A R^{2,3}$ Sleep impairment is common in $A R^{4,5}$ and is associated with severe nasal symptoms. ${ }^{6}$

By 2020 , rhinitis will affect at least $20 \%$ of the old-age population. ${ }^{7-11}$ Rhinitis in this age group has phenotypic specificities and treatment modalities including poly-medication. The effects of polypharmacy may contribute to congestion and dryness. ${ }^{12}$ Sex may also be a confounding factor in the elderly. The phenotypic characteristics and treatment of rhinitis in the elderly depend on ageing (physiology, immunology), socio-cultural barriers, environmental factors (urban vs rural), allergic and non-allergic multi-morbidities, ${ }^{13,14}$ drug availability and affordability, specific side effects to drugs in this age group, ${ }^{15}$ and health systems as well as type of care. However, rhinitis burden in the elderly is an under-recognized and under-treated problem. ${ }^{8}$ Important demographic changes are expected in the European population. It is therefore crucial to study the phenotype and treatment of rhinitis-asthma multimorbidity in this age group in different European regions in order to (i) provide new concepts and hypotheses and (ii) offer new diagnosis and management strategies to reduce health and social inequalities. 
Measures of AR control include symptom scores, control scores and patients' self-administered visual analogue scales (VAS). ${ }^{11,16-23}$ VAS, a psychometric response scale for subjective characteristics or attitudes, has been successfully used in many diseases including AR. Severe chronic upper airway disease (SCUAD) defines uncontrolled AR patients despite optimal pharmacotherapy. ${ }^{24}$ The Control of Allergic Rhinitis and Asthma Test (CARAT) ${ }^{25-28}$ is the only selfadministered questionnaire to quantify the control of both $A R$ and asthma concurrently. It consists of 10 questions on upper and lower airway symptoms, sleep interference, activity limitation, and the need to increase medication over a 4-week period. CARAT meets all items of the COSMIN (COnsensus-based Standards for the selection of health Measurement INstruments) checklist. $^{29-31}$ CARAT was developed and validated in Portugal and has been translated and culturally adapted in over 25 languages and nine countries (Belgium, Brazil, France, Germany, Greece, India, Italy, the Netherlands and Ukraine). Web and smartphone versions have been developed, and an open model of distribution contributes to its dissemination.

European Innovation Partnerships (EIPs) bring together all relevant actors at European Union (EU), national and regional levels to: (i) step up research and development efforts; (ii) coordinate investments in demonstration and pilots; (iii) anticipate and fast-track any necessary regulation and standards; and (iv) ensure that any breakthroughs are quickly brought to the market. The goals of the European Innovation Partnership on Active and Healthy Ageing (EIP on AHA) are to enable European citizens to lead healthy, active and independent lives whilst ageing. The EIP on AHA includes 74 Reference Sites.

MACVIA-France (Fighting chronic diseases for active and healthy ageing in France) is a reference site of the EIP on $\mathrm{AHA}^{32,33}$ It initiated the project "Integrated Care Pathways for airway diseases (AIRWAYS ICPs)". ${ }^{34,35}$ AIRWAYS ICPs aims to develop multi-sectoral ICPs for rhinitis and its multi-morbidities in the elderly, implementing emerging technologies for individualized and predictive medicine. ${ }^{35} \mathrm{~A}$ patient-centred mobile application (app for iOS and Android smartphones) has been developed. ${ }^{6,36}$ This app (Allergy Diary) uses VAS scores and enables the daily assessment of rhinitis and asthma control by patients themselves. $^{37,38}$ It will also include a Clinical Decision Support System (CDSS). ${ }^{22}$ The Allergy Diary is available for free download in 21 countries and 16 languages and has already been tested by over 8,000 users of all ages. Real-time data from users' smartphones can be stored and retrieved in a functional database. This EIP on AHA Synergy project has been developed between Action Groups of the EIP on AHA to build bridges for innovation in AHA. ${ }^{39}$ The Allergy Diary also includes CARAT.

Regional organizations engaged in the EIP on AHA were proposed to apply for a grant in order to facilitate the transfer of innovative practices (Twinning) for implementation in other regions (http://www.scale-aha.eu/news.html). The aim of this initiative is to facilitate the deployment of large-scale digitally-enabled innovative solutions for health and care delivery to the ageing population. It therefore contributes to the European Scaling Up Strategy of the EIP on AHA, already initiated by MACVIA-ARIA. ${ }^{40}$

\section{2 | OBJECTIVES OF THE MACVIA-ARIA TWINNING}

The transfer of innovative practices (Twinning) aims to transfer and implement (i) the Allergy Diary developed by MACVIA-LR ${ }^{37,38}$ and (ii) CARAT $^{25-28}$ to the different EIP on AHA Reference Sites. Other tools may also be used.

The longer-term aim of the Twinning is (i) to provide care pathways for individualized and predictive medicine for rhinitis and asthma multimorbidity in the elderly, ${ }^{36}$ (ii) to extend the study to sleep impairment in AR and asthma and (iii) to assess interactions of allergen exposure and air pollution. Moreover, the Twinning will allow Reference Sites from different areas of Europe to interact. This will increase knowledge, enable the transfer of know-how and support the establishment of local structured thematic networks on respiratory diseases sharing tools, indicators and knowledge that are available in the EU context (Table 1).

Although the vast majority of Reference Sites will work on the main aim of the Twinning (rhinitis and asthma multimorbidity in the elderly), some will have a different Twinning process to reinforce the project (Table 2).

As the study will last 1 year-to account for differences in allergen exposure - the starting data are not necessarily the same in all countries and new Reference Sites can join the Twinning within the next 6 months.

TABLE 1 Objectives of the twinning

General objectives

To compare phenotypic characteristics of rhinitis and asthma multimorbidity in adults and the elderly using validated ICT tools (Allergy Diary and CARAT) in EIP on AHA Reference Sites across Europe to better understand, diagnose and manage rhinitis and assess its burden in the elderly

Specific objectives

To assess the percentage of adults and elderly who are able to use the Allergy Diary:

Cross-sectional study: The study will include all users recruited by Reference Sites over a period of 1 year. All baseline characteristics will be analysed. Phenotypic characteristics and treatment of rhinitis and asthma multimorbidity in the elderly will be compared with those of adults

Longitudinal study: The study will include all users recruited by Reference Sites over a period of 1 year who have reported more than 1 day of VAS. VAS scores will be analysed. This part of the study may provide some insight into the differences between the elderly and adults in terms of response to treatment and practice

To better understand the methodological problems in this new type of observational study, and particularly age-dependent problems with ICT 
TABLE 2 Complementary activities of the twinning

- Andalucia will contribute to the mHealth assessment strategy and will test the quality of the mobile health app (Allergy Diary) (http://www.calidadappsalud.com/en).

- Northern Ireland will test another aspect of rhinitis and asthma multimorbidity (Fit at work with rhinitis) as uncontrolled allergic and non-AR has a major impact on work productivity. ${ }^{2,41-45}$

- Porto4Ageing will also contribute to (i) the implementation of CARAT in the Allergy Diary app for European countries with completed cultural adaptation processes (the Netherlands, Belgium, Germany, Greece, Ukraine, Italy, France) ${ }^{25-28}$ and (ii) the analysis of long-term longitudinal variability of CARAT scores and its associations with the MASK VAS

- The HealthRegion CologneBonn will help with the ethical aspects of the Twinning.

- The Trentino reference site will explore the advocacy of MACVIA study results within the Trentinosalute 4.0 Competence Centre on digital health.

\section{3 | ORIGINATOR AND ADOPTER ORGANISATIONS}

There are two types of organizations involved (Table 3):

- The "Organization transferring the innovative practice" (originator organization): the organization with the experience and knowhow developed in a particular field of intervention, awarded Reference Site status in the 2016 call and included in the innovative practices repository of the EIP on AHA (https://ec.europa.eu/eip/ ageing/repository_en).

- The "Organization adopting the innovative practice" (receiving/ adopter organization): the organization that will receive the innovative practice and deploy/implement it in its territory. This is the organization that was awarded Reference Site status in the 2016 call and that will benefit from the experience and know-how developed by the "organization transferring an innovative practice" in a particular field of intervention.

There will also be Reference Sites that will help to perform the Twinning. The MACVIA-ARIA Twinning mainly includes Reference Sites but certain other sites are also included (Figure 1).

All Reference Sites wishing to join the MACVIA-ARIA Twinning at a later stage are welcome.

In France, Italy, Germany, Lithuania, Poland, Portugal and Turkey, the Twinning will be carried at a national level with the Allergy Society and national health authorities of the country.

\section{4 | MACVIA-ARIA TWINNING METHODOLOGY}

\subsection{Tools}

The Allergy Diary will be used in all centres except for Andalucia. It is currently available on cell phones and also on tablets for health-care professionals in English (Allergy Diary Companion). ${ }^{37,38}$ Translations are pending. It includes EQ-5D, ${ }^{46}$ the WPAI-AS questionnaire ${ }^{47-49}$ and, in some countries, CARAT ${ }^{26,28,50}$ (when available in electronic form).

\subsubsection{Allergy diary}

\section{App (ANDROID and IOS)}

The Allergy Diary collects information on AR symptoms experienced (nasal and ocular), disease type (intermittent/persistent), how symptoms impact users' lives, and type(s) of AR treatment used (Table S1, Appendix S1). ${ }^{6}$

Geolocalized users assess their daily symptom control using the touchscreen functionality on their smart phone to click on five consecutive VAS (i.e. general, nasal and ocular symptoms, asthma and work) (Appendix S2).

Medications are also recorded daily (Appendix S3). Mobile phone messaging facilitates the management of AR, providing prompts to assess disease control, take medication, and visit a health care provider if appropriate.

The system was initially deployed in 15 European countries and in 15 languages (translated and back-translated, culturally adapted and legally compliant). It is now also available in Australia, Brazil, Canada, Mexico, Switzerland and Turkey. The system is currently being prepared for the Czech Republic.

Several observational studies have been carried out using the Allergy Diary.

- The Allergy Diary (Android and iOS) is user-friendly and has been tested for AR and conjunctivitis in over 5,000 users. The simple baseline questionnaire administered by cell phones allows the identification of phenotypic differences between a priori defined rhinitis and asthma multimorbidity groups and proposes novel concepts on AR. ${ }^{6}$

- The VAS reporting has been validated (Caimmi et al., submitted).

- Work productivity can be assessed daily (VAS) and there is a highly significant correlation between rhinitis control and work. ${ }^{39}$

- A cross-sectional observational study enables the differentiation of treatment strategies in AR (Bousquet et al., in preparation).

- Over $5 \%$ of Allergy Diary users are $\geq 65$ years of age.

\section{2 | Outcomes}

In this observational study, all subjects will fill in the following:

- Baseline characteristics (Table 5).

- EQ5D ${ }^{46}$ which can be used in the elderly.

- Treatments (Appendix S3).

- Four consecutive VAS measurements (general, nasal and ocular symptoms, asthma) (Appendix S2).

In addition, adults will fill in:

- The Work Productivity and Activity Impairment Allergic Specific Questionnaire (WPAI-AS) ${ }^{47,51}$ (Appendix S4).

- VAS for work (Appendix S2). 
TABLE 3 Originator and adopters of the Twinning

Originator
1. MACVIA-France
J Bousquet, S Arnavielhe, A Bedbrook, C Cartier, P Demoly,
G Onorato, R Jaquet, D Laune, F Viart
Adopters
2. Andalucia
AM Carriazo, J Ferrero
3. Aragon
R Angles
4. Campania
M Illario, M Triggiani, C Stellato, A Vatrella, G De Feo
5. Catalonia
A Dedeu Baraldès, M Olivé Elias, JM Anto, V Cardona, J Mullol,
A Valero
6. City of Helsinki
T Haahtela, T Strandberg, E Valovirta, J Salimaki, S Toppila-Salmi,
J Karjalainen, T Vasankari
7. Coimbra
J Malva, A Todo Bom, C Robalo-Cordeiro, M Morais Almeida,
MT Veríssimo, A Mota-Pinto
8. Heraklo
8. Heraklion
EP Prokopakis

\section{HealthRegion CologneBonn}
R Mösges, L Klimek, T Bieber, A Zurkuhlen, O Pfaar, T Zuberbier, KC Bergmann

10. Life Tech Valley

I Lieten, PW Hellings, C Bachert
11. Liguria
G Passalacqua, E Bacci, L Bertorello
12. Lodz
P Kuna, M Bochenska-Marciniak, M Kupczyk, P Lacwik
13. Medical Delta
NA Guldemond, NH Chavannes, R Gerth van Wijk, WJ Fokkens
14. Milan Metropolitan - Bergamo Province
M Romano, M Sorlini, AC Pozzi, D Lauri, F Corti, G Levato, M Nalin,
I Baroni

15. NHS 24

A Sheikh, A Custovic

16. Northern Ireland

I Young, E Colgan

17. Olomouc

V Kolek, Z Gutter, M Sova

18. Pays de la Loire

A Magnan, J Hajjam, L Colas

19. Porto

J Fonseca, M Costa, AM Pereira

20. Puglia

MT Ventura

(Continues)
TABLE 3 (Continued)

\begin{tabular}{l} 
21. Regione Piemonte \\
C Bucca, G Moda, G Rolla, A Romano, V Tibaldi \\
22. Region of Southern Denmark \\
C Bindslev-Jensen, E Eller, C Wanscher \\
23. Région Nouvelle Aquitaine \\
I Bosse \\
24. Turkey (Global Alliance against Chronic Respiratory Diseases \\
Regional Network) \\
A Yorgancioglu, B Gemicioglu, C Cingi, O Kalayci, F Kalyoncu \\
25. ARIA Sweden \\
M Wickman, E Melén \\
26. ARIA Lithuania \\
A Valiulis, R Dubakiene, R Emuzyte, V Kvedariene \\
27. Australia \\
\hline S Bosnic-Anticevich, RE O'Hehir \\
28. Brazil \\
AA Cruz \\
29. Mexico \\
D Larenas-Linnemann \\
30. Argentina \\
JC Ivancevich \\
\hline
\end{tabular}

\subsubsection{Printing of app data using a computer}

Patients cannot give access of their electronic data to a HCP due to privacy policies. However, they can print the daily control of their disease as well as their medication details that they filled in in the Allergy Diary. The procedure is as follows (Figure 2):

\subsection{2 | CARAT}

CARAT will be implemented in the Allergy Diary app for European countries with completed cultural adaptation processes (the Netherlands, Belgium, Germany, Greece, Ukraine, Italy, France). Every 2-4 weeks, participants with rhinitis and asthma will be prompted to fill in the CARAT questionnaire.

\subsection{3 | The physician's questionnaire}

For some patients, physicians will fill in a questionnaire that includes the questions of the Allergy Diary and of CARAT (Table 4).

The questionnaire will be filled in directly using the ARIA website.

\section{3 | Ethics}

The terms of use have been translated into all languages and customized according to the country's legislation. They allow the use of the results for research purposes. The example of the UK terms of use is given in Appendix S5. ${ }^{39}$ The data are anonymized except for 


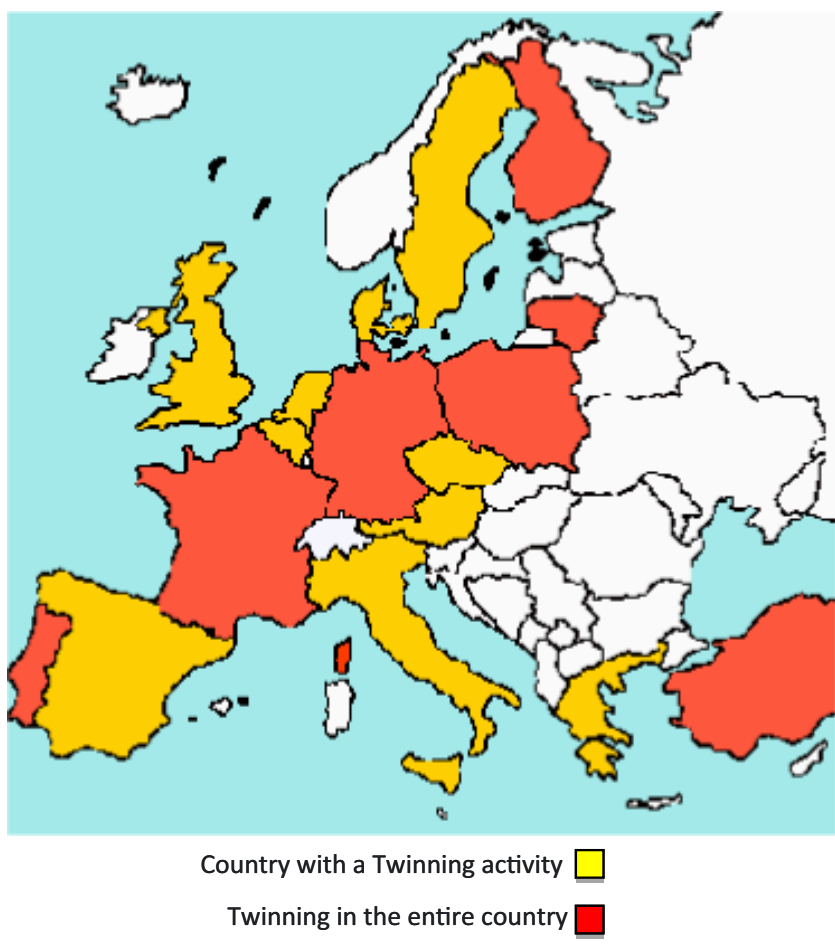

FIGURE 1 Twinning of the Allergy Diary in EIP on AHA Reference Sites (15-11-2016) [Colour figure can be viewed at wileyonlinelibrary.com]

the geolocalized data that are never totally anonymous. The European Commission's Article 29 Working Party stated that geolocation information is personal data (http://ec.europa.eu/newsroom/just/ite m-detail.cfm?item_id=50083) and that information can only be collected, shared, or stored with people's express consent. This is the case for MASK as users agree on geolocation in the terms of use of the app. Moreover, geolocation is optional and the user can allow it or not on his/her cell phone. Geolocation can be removed at any time. The problem of privacy due to geolocation was examined by the lawyers of each of the countries in which MASK has been launched and it was found to be in accordance with the existing laws. Moreover, geolocation is not used in the data mining process neither is the phone IP.

The Allergy Diary is a CE1 medical device and does not require ethical approval. An ethical agreement has been approved by a German ethics committee for the questionnaire. This ethical agreement will serve for all EU countries.

A participation agremeent to be signed by the patient has been proposed.

\section{4 | Possible biases}

As in any other observational study, the absence of randomization may be a source of relevant biases. ${ }^{52}$ However, observational studies reflect "real-world" use and practice more closely than randomized control trials (RCTs) in terms of the heterogeneous patient populations included and medical interventions. ${ }^{53}$ They can provide clinically relevant information not necessarily provided by RCTs. Given the limitations of an observational study approach, it is important to optimize their study design to maximize their validity. In particular, known causes of bias and confounding should be measured. ${ }^{53}$

However, this initiative was not designed to compare questionnaires with apps. A bias might be introduced because app users provide self-reported information in an uncontrolled setting. However, a recent systematic review has assessed the impact that smartphone and tablet apps as a delivery mode have on the quality of survey questionnaire responses compared to any other traditional alternative delivery mode. The review showed that apps might not affect data equivalence as long as the intended clinical application of the survey questionnaire, its intended frequency of administration and the setting in which it was validated remain unchanged. ${ }^{54}$

\subsection{Timeframe for procurement/implementation until 2018}

- The adopters will use freely available existing tools including (i) the Allergy Diary (Apple app Store and Google Play Store) and (ii) the questionnaire filled in by physicians.

- The Allergy Diary is available in 21 countries (Austria, Australia, Belgium, Brazil, Canada, Denmark, Finland, France, Germany, Greece, Italy, Lithuania, Mexico, the Netherlands, Poland, Portugal, Spain, Sweden, Switzerland, Turkey and the UK) and languages (national languages plus Catalan and Finnish Swedish). It can be implemented immediately. For other countries, translation, back-translation, cultural adaptation and legal compliance all require approximately 3-6 months.

- The phenotype, EQ-5D (MAFEIP ${ }^{39,55}$ ) and AR/asthma medication lists (IMS list customized for each country) are included in the Allergy Diary.

\subsection{Action/implementation plan}

Three protocols can be implemented (Table 5).

\subsubsection{Deployment of the app to the different Reference Sites (RS)}

Immediate and free access (Apple app Store and Google Play Store) is available for 21 countries, from 3 to 6 months for other countries.

\subsection{2 | Centres participating in the Twinning}

Each Reference Site will select physicians (with training in allergy) who work in out-patient clinics, in hospitals and/or in private practice. A combination of both practices would be optimal. All physicians will be volunteers for the study. There will be no compensation. 
1- Open the Allergy Diary app and choose "Show Data on Computer" in the main menu

2- Go to www.macvia-aria-allergy-diary.com/data on your PC/Laptop (enter this URL in the address bar of the browser from your PC/Laptop)

3- Scan the QR code with the Allergy Diary app

4- The screen with your personal data can be seen

5- And you can also print these data (see figure below).

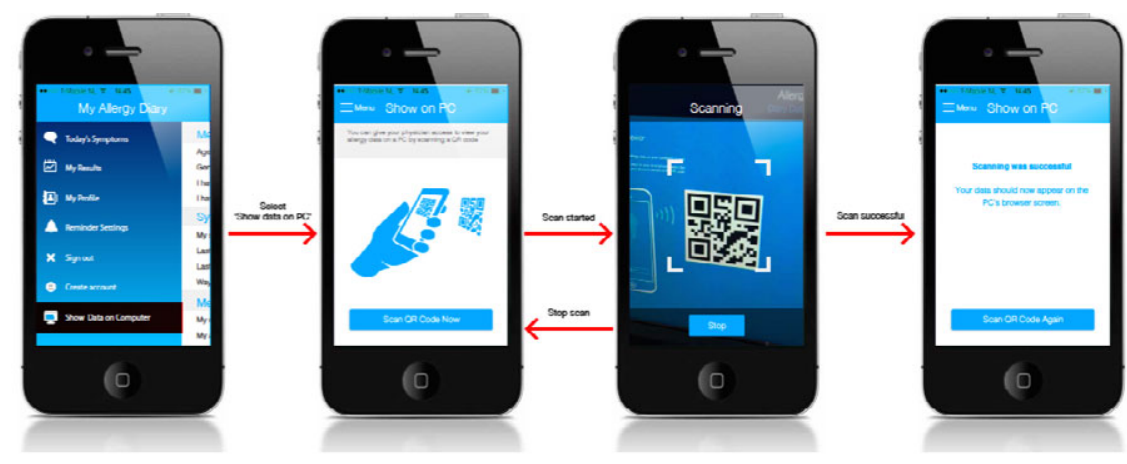

'HOW ARE YOUR ALLERGIES AFFECTING YOU TODAY?' Allergy Diary

FIGURE 2 Transfer of patient information on a computer and printed information

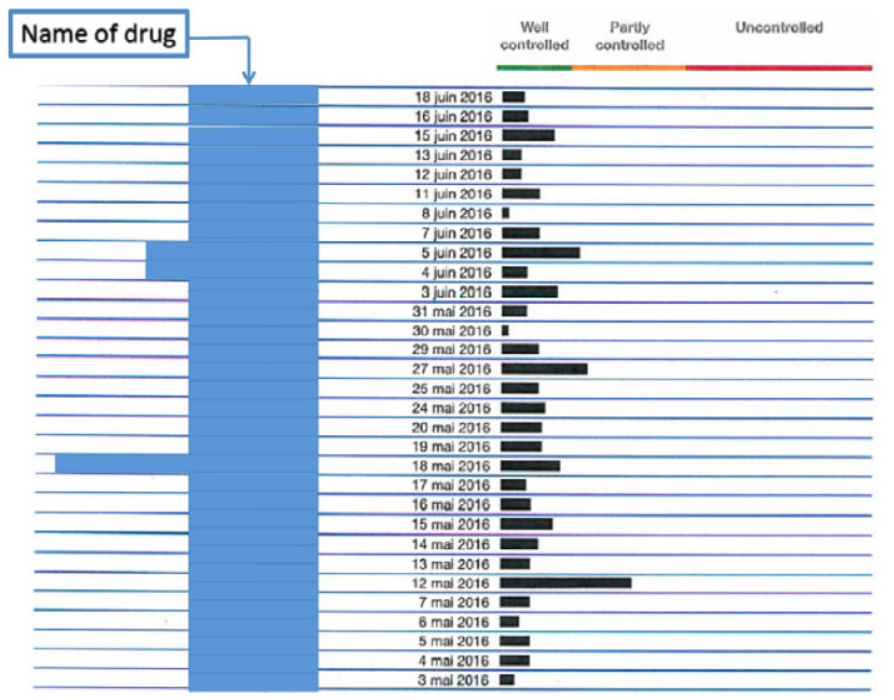

- Protocol 1: The physician enrolling the user asks the patient to use the Allergy Diary and checks that this has been done and that the user has agreed to be geolocalized. This latter point is of importance as it will help to analyse differences between regions. Both specialists and physicians working in primary care can participate in the Twinning.

- Protocol 2 (allergists) to enrol at least 10 adults and 5 old age persons.

The duration of enrolment is 12 months to account for variability in allergen exposure during the year. Thus, the study can be initiated in Reference Sites from 1 January, 2017 to 1 July, 2017.

\subsection{4 | Study protocol}

Two different protocols can be used (and probably mixed in the same region) depending on the decision of the physician.
- Only patients who have not registered to the app will be enrolled.

- The physician enrolling the user will complete the questionnaire and will profile his/her patient in a computer by answering an online questionnaire (ARIA-EUFOREA website)

- The physician will end the profile by adding a random alphanumerical code to his/her patient profile (as we process during 
TABLE 4 Questionnaire to be filled in by the physician

(A)

\begin{tabular}{|c|c|c|c|c|}
\hline \multicolumn{4}{|c|}{$\begin{array}{l}\text { MACVIA- ARIA } \\
\text { Physician's Questionnaire }\end{array}$} & \multirow{2}{*}{ Date $: \_/ I_{-}$} \\
\hline \multicolumn{3}{|l|}{ 1- Date of birth } & LIST WITH YEARS_/_/_ & \\
\hline \multirow{2}{*}{\multicolumn{3}{|c|}{ 2- Sex }} & Male & Female \\
\hline & & & O & O \\
\hline \multicolumn{5}{|c|}{ 3- The patient is suffering from } \\
\hline \multicolumn{4}{|c|}{ Current allergic rhinitis } & $\square$ \\
\hline \multicolumn{4}{|c|}{ Current asthma (within the past 3 months) } & $\square$ \\
\hline \multicolumn{4}{|l|}{ Conjunctivitis } & $\square$ \\
\hline \multicolumn{4}{|c|}{ Non-allergic rhinitis } & $\square$ \\
\hline \multicolumn{4}{|c|}{ Asthma previously in life } & $\square$ \\
\hline \multicolumn{4}{|c|}{ Current atopic dermatitis } & $\square$ \\
\hline \multicolumn{5}{|c|}{ 4- Impact of allergic symptoms } \\
\hline & & Yes & No & Don't know \\
\hline \multicolumn{2}{|c|}{ Symptoms affect sleep } & O & 0 & Q \\
\hline \multicolumn{2}{|c|}{ Symptoms restrict daily activities } & O & O & O \\
\hline \multicolumn{2}{|c|}{ Symptoms restrict work or participation in school } & O & O & Q \\
\hline \multicolumn{2}{|c|}{ Symptoms are troublesome } & O & O & 0 \\
\hline \multirow{2}{*}{\multicolumn{5}{|c|}{$\begin{array}{l}\text { 5- CARAT Questionnaire Question 5- A) should be read to the patient with the patient choosing the answer. There should be } \\
\text { no "interpretation": the physician should not fill in the questionnaire on behalf of the patient. } \\
\text { A) Due to your allergic respiratory diseases (asthma, rhinitis, allergies) in the last four weeks, on average, how many } \\
\text { times did you have: }\end{array}$}} \\
\hline & & & & \\
\hline \multicolumn{2}{|l|}{ 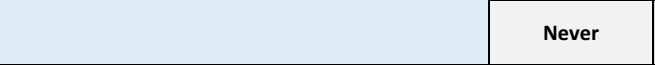 } & $\begin{array}{l}\text { Up to } 2 \text { days } \\
\text { per week }\end{array}$ & $\begin{array}{c}\text { More than } 2 \\
\text { days per week }\end{array}$ & $\begin{array}{c}\text { Almost every } \\
\text { day }\end{array}$ \\
\hline \multicolumn{2}{|l|}{ Blocked nose? } & O & Q & O \\
\hline Sneezing? & 0 & O & O & O \\
\hline Itchy nose? & O & 0 & O & O \\
\hline Runny nose? & O & O & O & O \\
\hline Shortness of breath/dyspnoea? & O & O & O & O \\
\hline Wheezing in the chest? & O & O & Q & O \\
\hline Chest tightness during physical exercise? & O & Q & O & 0 \\
\hline Tiredness/limita & O & O & O & Q \\
\hline Waking up in the & 0 & O & 0 & O \\
\hline $\begin{array}{l}\text { 5- CARAT Quest } \\
\text { no "interpretatic } \\
\text { B) Due to your }\end{array}$ & $\begin{array}{l}\text { to the patient } \mathrm{w} \\
\text { questionnaire on } \\
\text {, rhinitis, allergi }\end{array}$ & $\begin{array}{l}\text { the patient ch } \\
\text { ehalf of the pat } \\
\text { ) in the last fou }\end{array}$ & $\begin{array}{l}\text { osing the answer } \\
\text { nt. } \\
\text { weeks, how man }\end{array}$ & $\begin{array}{l}\text { There should be } \\
\text { times did you: }\end{array}$ \\
\hline & $\begin{array}{l}\text { I'm not taking } \\
\text { any medicine }\end{array}$ & Never & $\begin{array}{l}\text { Less than } 7 \\
\text { days }\end{array}$ & 7 or more days \\
\hline $\begin{array}{l}\text { Increase the use } \\
\text { medicine? }\end{array}$ & 0 & 0 & 0 & O \\
\hline 6- Allergic sensit & e past 5 years) & & & \\
\hline Skin test & & & & 0 \\
\hline Specific lgE & & & & O \\
\hline Skin test + Speci & & & & O \\
\hline Not diagnosed & & & & O \\
\hline 7- Positive test $f$ & & & & \\
\hline House dust mite & & & & $\square$ \\
\hline Alder & & & & $\square$ \\
\hline Hazel & & & & $\square$ \\
\hline Grass pollen & & & & $\square$ \\
\hline
\end{tabular}

clinical study). This code will be manually registered by the patient on his/her smartphone at the downloading step of the app.

- Hence, physicians' profile data and patients' self-recorded symptoms data will be reconciled for analysis.

○ The physician will ask the person to use the Allergy Diary and will check onsite that this has been done and that the user has agreed to be geolocalized.

- Protocol 3: Fit at work: Some enterprises (NHS Northern Ireland, Hôpital de Valenciennes, France) are participating in an analysis of work productivity.
For the three protocols, there is potential for direct benefit for the patients and the physicians.

As an example, during the patient's next visit, the physician will see a graph indicating the level of control, the compliance to the treatment and the treatments actually taken by the patient.

Moreover, the first results of the Allergy Diary are extremely interesting. ${ }^{3,6}$ Unpublished data show that the care pathways of patients with AR and asthma multimorbidity should be reconsidered as most patients self-medicate. 
TABLE 4 (Continued)

(B)

\begin{tabular}{|c|c|}
\hline Cypress pollen & $\square$ \\
\hline Birch pollen & $\square$ \\
\hline Other tree pollen & $\square$ \\
\hline Parietaria pollen & $\square$ \\
\hline Ragweed pollen & $\square$ \\
\hline Cat & $\square$ \\
\hline Dog & $\square$ \\
\hline Other inhalant allergen & $\square$ \\
\hline Food allergen & $\square$ \\
\hline Don't know & $\square$ \\
\hline \multicolumn{2}{|l|}{ 8- Prescribed treatment } \\
\hline \multicolumn{2}{|l|}{ (Scrolling list) Add "no treatment" in the scrolling list } \\
\hline \multicolumn{2}{|l|}{ 9- The patient currently receives immunotherapy for: } \\
\hline House dust mites & $\square$ \\
\hline Alder & $\square$ \\
\hline Hazel & $\square$ \\
\hline Grass pollen & $\square$ \\
\hline Cypress pollen & $\square$ \\
\hline Birch pollen & $\square$ \\
\hline Other tree pollen & $\square$ \\
\hline Parietaria pollen & $\square$ \\
\hline Ragweed pollen & $\square$ \\
\hline Cat & $\square$ \\
\hline Dog & $\square$ \\
\hline Other inhalant allergen & $\square$ \\
\hline None & $\square$ \\
\hline \multicolumn{2}{|l|}{ 10- Current immunotherapy is administered by: } \\
\hline SCIT & $\square$ \\
\hline SLIT drops & $\square$ \\
\hline SLIT tablets & $\square$ \\
\hline Oralair & $\square$ \\
\hline Grazax & $\square$ \\
\hline \multicolumn{2}{|l|}{ 11- Date of initiation of immunotherapy } \\
\hline \multicolumn{2}{|l|}{ Month/Year (Scrolling list) } \\
\hline \multicolumn{2}{|l|}{ 12- Education } \\
\hline Secondary school or less & O \\
\hline Sixth form or college & O \\
\hline Bachelor degree & O \\
\hline Postgraduate & O \\
\hline Missing & O \\
\hline \multicolumn{2}{|l|}{ 13- Work Status } \\
\hline Currently full time employed & O \\
\hline On light duty or some restricted work assignment or part time & O \\
\hline Paid leave/sick leave & O \\
\hline Unemployed because of other reason & O \\
\hline Student (school, college, university) & Q \\
\hline Keeping house/homemaker & O \\
\hline Retired & O \\
\hline On disability & O \\
\hline Missing & O \\
\hline
\end{tabular}

\subsection{5 | Real-time analysis of the data}

The analysis will be based on the pilot study of the Allergy Diary (manuscript submitted and manuscript in preparation), and real-time analysis across the different Reference Sites will be available.

\section{5 | EXPECTED OUTCOMES OF THE TWINNING ACTIVITIES}

1. Phenotypic characteristics: The Allergy Diary collects information on AR symptoms and allergic multi-morbidities experienced (nasal and ocular, asthma), on how symptoms impact users' lives, and on the type(s) of AR and asthma treatments used. The study provides a unique opportunity (i) to investigate the phenotype of rhinitis and asthma multimorbidity in the elderly in Europe, (ii) to study differences with other age groups using data on file and (iii) to make comparisons across countries.

2. Treatment of rhinitis and asthma multimorbidity and disease control: The control of rhinitis appears to differ depending on the age group. The study will show differences (i) with other age groups using data on file and (ii) between regions, allowing optimization of care pathways.

3. Use of the EQ-5D allows quality-of-life and utilities data to be assessed. It is a MAFEIP tool. ${ }^{39,55}$ 
TABLE 5 Protocols of the Twinning

\begin{tabular}{|c|c|c|c|}
\hline & $\begin{array}{l}\text { Protocol } 1 \\
\text { Short version }\end{array}$ & $\begin{array}{l}\text { Protocol } 2 \\
\text { Long version }\end{array}$ & $\begin{array}{l}\text { Protocol } 3 \\
\text { Fit at work }\end{array}$ \\
\hline Allergy Diary & + & + & + \\
\hline EQ5D, WP-AIAS & Optional & + & + \\
\hline $\begin{array}{l}\text { Physician's } \\
\text { questionnaire }\end{array}$ & & + & Optional \\
\hline $\begin{array}{l}\text { Ethical } \\
\text { committee }\end{array}$ & Not needed & Obtained & Needed if physician's questionnaire \\
\hline $\begin{array}{l}\text { Participation } \\
\text { agreement }\end{array}$ & Terms of use of app & $\begin{array}{l}\text { Participation agreement form } \\
\text { signed by patients }\end{array}$ & \\
\hline Recruitment & $\begin{array}{l}\text { Any user. Persons attending clinic } \\
\text { visits can be included }\end{array}$ & $\begin{array}{l}\text { Persons with rhinitis from clinics } \\
\text { with a diagnosis of AR made } \\
\text { by a specialist (with skin } \\
\text { tests and/or specific IgE) }\end{array}$ & $\begin{array}{l}\text { Users in settings participating } \\
\text { in the "Fit at work" protocol }\end{array}$ \\
\hline
\end{tabular}

4. Comparison between regions (or countries depending on the health system)

5. Comparison between rural and urban environments.

6. Care pathways: the results of the study will be used to develop region-specific care pathways (AIRWAYS ICPS) using a personalized medicine approach. Self-management strategies will be of great importance.

7. Knowledge and know-how transferred: The epidemic wave of rhinitis in adults (over $25 \%$ of the European population) is now reaching the elderly. It is essential to better characterize, understand and manage this disease that affects social life and causes serious discomfort for sufferers. A pan-European view of the problem will allow a cost-effective and socially acceptable management of this disease. The Allergy Diary, developed by the MACVIA France Reference Site, is freely available for subjects in most European countries. The app will be deployed by the Reference Site Collaborative Network for transfer of knowledge. ${ }^{40,56}$

8. Rhinitis and asthma multimorbidity exemplifies why a lifecourse approach to AHA is the key to effective interventions that are sustainable for the public health systems.

\section{6 | FUTURE DEVELOPMENTS}

- Sleep is impaired in rhinitis and asthma ${ }^{4,5}$ and the Allergy Diary has been found to accurately assess sleep impairment. ${ }^{6}$ More data are needed and the app is being improved to include sleeprelated questions.

- To correlate Allergy Diary data with allergen exposure using classical methods such as pollen counts or Google Trends-derived methods. ${ }^{57}$

- To better understand the links between AR and pollution in order to provide preventive and treatment strategies to reduce $A R$ burden.

\section{REFERENCES}

1. Bousquet J, Khaltaev N, Cruz AA, et al. Allergic Rhinitis and its Impact on Asthma (ARIA) 2008 update (in collaboration with the
World Health Organization, GA(2)LEN and AllerGen). Allergy. 2008;63(Suppl. 86):8-160.

2. Vandenplas O, D'Alpaos V, Van Brussel P. Rhinitis and its impact on work. Curr Opin Allergy Clin Immunol. 2008;8:145-149.

3. Bousquet J, Bewick $M$, Arnavielhe $S$, et al. Work productivity in rhinitis using cell phones: the MASK pilot study. Allergy. 2017;72:1475-1484.

4. Leger D, Annesi-Maesano I, Carat F, et al. Allergic rhinitis and its consequences on quality of sleep: an unexplored area. Arch Intern Med. 2006;166:1744-1748.

5. Muliol J, Maurer M, Bousquet J. Sleep and allergic rhinitis. J Investig Allergol Clin Immunol. 2008;18:415-419.

6. Bousquet J, Caimmi D, Bedbrook A, et al. Pilot study of mobile phone technology in allergic rhinitis in European countries. The MASK-rhinitis study. Allergy. 2017;72:857-865.

7. Bousquet J, Samolinski B. Allergy and active and healthy ageing. In: Akdis C, Agache I, Demoly P, Hellinbgs P, Muraro A, Papadopoulos $\mathrm{N}$, et al., eds. Global Atlas of Allergy European Academy of Allergy and Clinical Immunology. 2014:379-381.

8. Morais-Almeida M, Pite H, Pereira AM, et al. Prevalence and classification of rhinitis in the elderly: a nationwide survey in Portugal. Allergy. 2013;68:1150-1157.

9. Baptist AP, Nyenhuis S. Rhinitis in the elderly. Immunol Allergy Clin North Am. 2016;36:343-357.

10. Ventura MT, Gelardi M, D'Amato A, et al. Clinical and cytologic characteristics of allergic rhinitis in elderly patients. Ann Allergy Asthma Immunol. 2012;108:141-144.

11. Ohta $\mathrm{K}$, Bousquet PJ, Aizawa $\mathrm{H}$, et al. Prevalence and impact of rhinitis in asthma. SACRA, a cross-sectional nation-wide study in Japan. Allergy. 2011;66:1287-1295.

12. Sahin-Yilmaz AA, Corey JP. Rhinitis in the elderly. Clin Allergy Immunol. 2007;19:209-219.

13. Song WJ, Kim MY, Jo EJ, et al. Rhinitis in a community elderly population: relationships with age, atopy, and asthma. Ann Allergy Asthma Immunol. 2013;111:347-351.

14. Pite $\mathrm{H}$, Pereira AM, Morais-Almeida M, Nunes C, Bousquet J, Fonseca JA. Prevalence of asthma and its association with rhinitis in the elderly. Respir Med. 2014;108:1117-1126.

15. Hansen J, Klimek L, Hormann K. Pharmacological management of allergic rhinitis in the elderly: safety issues with oral antihistamines. Drugs Aging. 2005;22:289-296.

16. Bousquet PJ, Combescure C, Neukirch F, et al. Visual analog scales can assess the severity of rhinitis graded according to ARIA guidelines. Allergy. 2007;62:367-372

17. Di Lorenzo G, Pacor ML, Amodio E, et al. Differences and similarities between allergic and nonallergic rhinitis in a large sample of adult 
patients with rhinitis symptoms. Int Arch Allergy Immunol. 2011;155:263-270.

18. Lu D, Zhao Y, Zheng Y, et al. Evaluation of quality of life questionnaires for adult patients with moderate to severe allergic rhinitis. Am J Otolaryngol. 2011;32:494-498.

19. del Cuvillo A, Montoro J, Bartra J, et al. Validation of ARIA duration and severity classifications in Spanish allergic rhinitis patients - The ADRIAL cohort study. Rhinology. 2010;48:201-205.

20. Bousquet PJ, Bachert C, Canonica GW, et al. Uncontrolled allergic rhinitis during treatment and its impact on quality of life: a cluster randomized trial. J Allergy Clin Immunol. 2010;126:666-668.

21. Demoly P, Jankowski R, Chassany O, Bessah Y, Allaert FA. Validation of a self-questionnaire for assessing the control of allergic rhinitis. Clin Exp Allergy. 2011;41:860-868.

22. Bousquet J, Schunemann HJ, Hellings PW, et al. MACVIA clinical decision algorithm in adolescents and adults with allergic rhinitis. $J$ Allergy Clin Immunol. 2016;138:367-374.

23. Klimek L, Bergmann K, Biederman T, Bousquet J, Hellings $P$, , et al. Visual analogue scales (VAS): measuring instruments for the documentation of symptoms and therapy monitoring in allergic rhinitis in everyday health care. Position Paper of the German Society of Allergology. Allergo J Int. 2017;26:16-24.

24. Bousquet J, Bachert C, Canonica GW, et al. Unmet needs in severe chronic upper airway disease (SCUAD). J Allergy Clin Immunol. 2009;124:428-433.

25. Azevedo P, Correia de Sousa J, Bousquet J, et al. Control of Allergic Rhinitis and Asthma Test (CARAT): dissemination and applications in primary care. Prim Care Respir J. 2013;22:112-116.

26. Fonseca JA, Nogueira-Silva L, Morais-Almeida M, et al. Validation of a questionnaire (CARAT10) to assess rhinitis and asthma in patients with asthma. Allergy. 2010;65:1042-1048.

27. Nogueira-Silva L, Martins SV, Cruz-Correia R, et al. Control of allergic rhinitis and asthma test-a formal approach to the development of a measuring tool. Respir Res. 2009;10:52.

28. van der Leeuw S, van der Molen T, Dekhuijzen PN, et al. The minimal clinically important difference of the control of allergic rhinitis and asthma test (CARAT): cross-cultural validation and relation with pollen counts. NPJ Prim Care Respir Med. 2015;25:14107.

29. Mokkink LB, Prinsen CA, Bouter LM, Vet HC, Terwee CB. The COnsensus-based Standards for the selection of health Measurement INstruments (COSMIN) and how to select an outcome measurement instrument. Braz J Phys Ther. 2016;20:105-113.

30. Mokkink LB, Terwee CB, Gibbons E, et al. Inter-rater agreement and reliability of the COSMIN (COnsensus-based Standards for the selection of health status Measurement Instruments) checklist. BMC Med Res Methodol. 2010;10:82.

31. Mokkink LB, Terwee CB, Patrick DL, et al. The COSMIN study reached international consensus on taxonomy, terminology, and definitions of measurement properties for health-related patientreported outcomes. J Clin Epidemiol. 2010;63:737-745.

32. Bousquet J, Hajjam J, Piette F, et al. [The French reference sites of the European Innovation Partnership on active and healthy ageing]. Presse Med. 2013;42:1558-1561.

33. Bousquet J, Michel J, Standberg T, Crooks G, lakovidis I, Gomez M. The European Innovation Partnership on Active and Healthy Ageing: the European Geriatric Medicine introduces the EIP on AHA Column. Eur Geriatr Med. 2014;5:361-362.

34. Bousquet J, Addis A, Adcock I, et al. Integrated care pathways for airway diseases (AIRWAYS-ICPs). Eur Respir J. 2014;44:304323.

35. Bousquet J, Addis A, Agache I, et al. Integrated care pathways for airway diseases (AIRWAYS ICPs). Eur Respir J. 2014;44:304-323.

36. Bousquet J, Hellings PW, Agache I, et al. ARIA 2016: care pathways implementing emerging technologies for predictive medicine in rhinitis and asthma across the life cycle. Clin Transl Allergy. 2016;6:47.

37. Bourret R, Bousquet J, Mercier J, et al. MASK rhinitis, a single tool for integrated care pathways in allergic rhinitis. World Hosp Health Serv. 2015;51:36-39.

38. Bousquet J, Schunemann HJ, Fonseca J, et al. MACVIA-ARIA Sentinel NetworK for allergic rhinitis (MASK-rhinitis): the new generation guideline implementation. Allergy. 2015;70:13721392.

39. Bousquet J, Bewick M, Cano A, et al. Building bridges for innovation in ageing: synergies between action groups of the EIP on AHA. J Nutr Health Aging. 2017;21:92-104.

40. Bousquet J, Farrell J, Crooks G, et al. Scaling up strategies of the chronic respiratory disease programme of the European Innovation Partnership on Active and Healthy Ageing (Action Plan B3: Area 5). Clin Transl Allergy. 2016;6:29.

41. Vandenplas O, Van Brussel P, D'Alpaos V, Wattiez M, Jamart J, Thimpont J. Rhinitis in subjects with work-exacerbated asthma. Respir Med. 2010;104:497-503.

42. Hellgren J, Cervin A, Nordling S, Bergman A, Cardell LO. Allergic rhinitis and the common cold-high cost to society. Allergy. 2010;65:776-783.

43. Kakutani C, Ogino S, Ikeda H, Enomoto T. [Impact of allergic rhinitis on work productivity: a pilot study]. Arerugi. 2005;54:627-635.

44. Kim SY, Yoon SJ, Jo MW, Kim EJ, Kim HJ, Oh IH. Economic burden of allergic rhinitis in Korea. Am J Rhinol Allergy. 2010;24:e110e113.

45. Marcellusi A, Viti R, Incorvaia C, Mennini FS. [Direct and indirect costs associated with respiratory allergic diseases in Italy. A probabilistic cost of illness study]. Recenti Prog Med. 2015;106:517-527.

46. Konig HH, Bernert S, Angermeyer MC, et al. Comparison of population health status in six european countries: results of a representative survey using the EQ-5D questionnaire. Med Care. 2009;47:255261.

47. Bousquet J, Neukirch F, Bousquet PJ, et al. Severity and impairment of allergic rhinitis in patients consulting in primary care. J Allergy Clin Immunol. 2006;117:158-162.

48. Devillier P, Bousquet J, Salvator $H$, Naline E, Grassin-Delyle $S$, de Beaumont $\mathrm{O}$. In allergic rhinitis, work, classroom and activity impairments are weakly related to other outcome measures. Clin Exp Allergy. 2016;46:1456-1464.

49. Reilly MC, Zbrozek AS, Dukes EM. The validity and reproducibility of a work productivity and activity impairment instrument. Pharmacoeconomics. 1993;4:353-365.

50. Linhares DV, da Fonseca JA, Borrego LM, et al. Validation of control of allergic rhinitis and asthma test for children (CARATKids)-a prospective multicenter study. Pediatr Allergy Immunol. 2014;25:173-179.

51. Virchow JC, Kay S, Demoly P, Mullol J, Canonica W, Higgins V. Impact of ocular symptoms on quality of life (QoL), work productivity and resource utilisation in allergic rhinitis patients-an observational, cross sectional study in four countries in Europe. J Med Econ. 2011;14:305-314.

52. DiPietro NA. Methods in epidemiology: observational study designs. Pharmacotherapy. 2010;30:973-984.

53. Yang W, Zilov A, Soewondo P, Bech OM, Sekkal F, Home PD. Observational studies: going beyond the boundaries of randomized controlled trials. Diabetes Res Clin Pract. 2010;88(Suppl. 1):S3S9.

54. Marcano Belisario JS, Jamsek J, Huckvale K, O'Donoghue J, Morrison CP, Car J. Comparison of self-administered survey questionnaire responses collected using mobile apps versus other methods. Cochrane Database Syst Rev. 2015;27:MR000042. 
55. Boehler CE, de Graaf G, Steuten L, Yang Y, Abadie F. Development of a web-based tool for the assessment of health and economic outcomes of the European Innovation Partnership on Active and Healthy Ageing (EIP on AHA). BMC Med Inform Decis Mak. 2015;15 (Suppl 3):S4.

56. Calderon MA, Demoly $\mathrm{P}$, Casale $\mathrm{T}$, et al. Allergy immunotherapy across the life cycle to promote active and healthy ageing: from research to policies: an AIRWAYS Integrated Care Pathways (ICPs) programme item (Action Plan B3 of the European Innovation Partnership on active and healthy ageing) and the Global Alliance against Chronic Respiratory Diseases (GARD), a World Health Organization GARD research demonstration project. Clin Transl Allergy. 2016;6:41.

57. Bousquet J, Agache I, Anto J, et al. Google trends terms reporting rhinitis and related topics differ in European countries. Allergy. 2017;72:1261-1266

\section{SUPPORTING INFORMATION}

Additional Supporting Information may be found online in the supporting information tab for this article.

How to cite this article: Bousquet J, Agache I, Aliberti MR, et al. Transfer of innovation on allergic rhinitis and asthma multimorbidity in the elderly (MACVIA-ARIA) EIP on AHA Twinning Reference Site (GARD research demonstration project). Allergy. 2018;73:77-92. https://doi.org/10.1111/ all.13218 